\title{
SINTAGMA GNOSEOLÓGICO DE LA DEUDA ECOLÓGICA
}

Eduardo Mantilla-Pinilla

Universidad Santo Tomás

Colombia

Adolfo Enrique Carbal-Herrera

Universidad de Cartagena

Colombia

Betsimar Gutiérrez-Suárez

Universidad Santo Tomás

Colombia

Leidy Tatiana Mejía-Mena Universidad Santo Tomás, Colombia 
Panorama Económico, Vol. 26 - No. 4 (Octubre - Diciembre de 2018), pp. 459-480

Eduardo Mantilla-Pinilla

Adolfo Enrique Carbal-Herrera

Betsimar Gutiérrez-Suárez

Leidy Tatiana Mejía-Mena

\title{
Sintagma gnoseológico de la deuda ecológica
}

\section{Resumen}

Este artículo sintetiza el sintagma gnoseológico de la deuda ecológica encontrado hasta la fecha. Para tal fin, se revisaron publicaciones indexadas en bases de datos reconocidas por Colciencias y libros pertinentes. Se encontró que el debate sobre la deuda ecológica ha sido sustentado por diferentes organizaciones y Estados desde la Cumbre de Rio de Janeiro en 1992, cuando se le dio relevancia; sin embargo, poco se ha trabajado en su materialización. Actualmente se sigue debatiendo el valor de la deuda ya que se trata de bienes naturales garantes de la vida humana, lo cual los hace invaluables y, dificulta la tasación de la deuda en un valor monetario.

Palabras clave: Deuda Ecológica, Eco-Deuda, Pasivo Ambiental, Huella Ecológica.

Clasificación JEL: Q2, Q4, M10

\section{Gnoseological syntagm of the ecological debt}

\begin{abstract}
This article synthesizes the gnoseological syntagm of the ecological debt found to date. To this end, publications indexed in databases recognized by Colciencias and relevant books were reviewed. It was found that the debate on the ecological debt has been supported by different organizations and States since the Rio de Janeiro Summit in 1992, when it became relevant; nevertheless, little has been worked on in its materialization. The value of the debt is currently being debated since it is natural assets that guarantee human life, which makes them invaluable and makes it difficult to assess the debt in a monetary value.

Keywords: Ecological Debt, nature- debt, environmental liability, environmental cost, ecological Footprint.
\end{abstract}

JEL Classification: Q2, Q4, M10

\section{Syntagm Gnoséologique de la dette écologique}

\section{Résumé}

Ce document vise à estimer les impacts du vieillissement de la population et de la dynamique du marché du travail sur les dépenses publiques de pension à court et moyen terme en simulant différents scénarios de formalité et de productivité du travail tenant compte des facteurs institutionnels du système de retraite Colombien. Il est conclu que l'augmentation de la formalisation de la maind'œuvre n'est pas suffisante pour réduire les dépenses publiques consacrées aux retraites, car la productivité du travail est la variable essentielle de la viabilité financière du système à moyen terme augmentation des salaires et des cotisations.

Mots-clés: Dette écologique, dette de la nature, responsabilité environnementale, coût environnemental, empreinte écologique.

Nomenclature JEL: Q2, Q4, M10 


\section{Sintagma gnoseológico de la deuda ecológica}

INFORMACIÓN DEL ARTíCULO

Recepción de artículo: 23/05/2018

Concepto de evaluación: 28/06/2018

Aceptación de artículo: 02/08/2018
Eduardo Mantilla-Pinilla* Universidad Santo Tomás, Colombia

Adolfo Enrique Carbal-Herrera Universidad de Cartagena, Colombia

Betsimar Gutiérrez-Suárez Universidad Santo Tomás, Colombia

Leidy Tatiana Mejía-Mena Universidad Santo Tomás, Colombia

\section{INTRODUCCIÓN}

La racionalidad equivocada de la explotación de la naturaleza, ha generado consecuencias ambientales y sociales, que han conllevado a diferentes autores a preguntarse sobre la retribución al daño recibido por las poblaciones más afectadas en su calidad de vida. Como es sabido, la mayoría de países no industrializado están endeudados con países industrializados, no obstante, el interrogante, ¿no fueron los países acreedores los que saquearon a los países no industrializados?, se apropiaron de activos ambientales, destruyeron parte de los ecosistemas y permeando sus culturas, provocando el empobrecimiento de los pueblos.

Una mirada regresiva de tal situación, conllevo a hablar de Deuda Ecológica, como concepto para compensar la deuda externa. En términos generales la deuda ecológica la determina el nivel de deterioro de la naturaleza por consumo de sus elementos renovables y no renovables y por descarga de desechos superando la capacidad de recuperación y equilibrio natural. Sin embargo, desde un enfoque de responsabilidades, se ha definido como la deuda de los países del norte con los del sur debido al usufructo y explotación de la naturaleza desde la época colonial, dando origen a múltiples discusiones conceptuales, lo que motiva una revisión documental en reconocimiento del sintagma gnoseológico de la "Deuda Ecológica", partiendo desde el análisis etimológico.

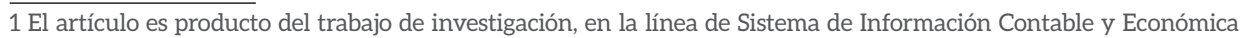
Ambiental del Grupo INDERCON, y un aporte para la Red de Investigación Contable para el Desarrollo "Red INCODE".

\footnotetext{
* Autor para correspondencia

Correos electrónicos: eduardo.mantilla@ustabuca.edu.co*, carbal125@yahoo.es, betsi.gutierrez13@gmail.com, statis_94@hotmail.com
} 
Si bien, este concepto nace en un discurso político, ha tomado fuerza con la discusión de diferentes autores, surgiendo en paralelo expresiones como "Pasivo Ambiental", con significado relativamente igual. La investigación en este artículo se convierte en la primera etapa del análisis e, insumo para posturas científicas frente a la Deuda Ecológica y Pasivo Ambiental, ya que no se dispone de instrumentos para su cálculo, siendo subjetivo todo valor que represente esta deuda y el pasivo.

Aspecto metodológico: La investigación se sustenta en la revisión de publicaciones indexadas en las bases de datos reconocidas por Colciencias como Scopus, Scielo y Redalyc, y libros de investigación, revisando más de 50 autores destacando que, la mayoría son latinoamericanos, lo que resalta una mayor preocupación por la temática en esta región del continente.

La búsqueda de la información se llevó a cabo organizando la ecuación de búsqueda en orden a "Deuda ecológica, deuda por contaminación, deuda por daño ambiental" haciendo uso de palabras clave como "indicadores ambientales, huella ecológica y pasivos ambientales", en su equivalente "Ecological debt, pollution debt, debt for environmental damage" using keywords such as "environmental indicators, ecological footprint and environmental liabilities". A su vez se consultó la etimología, sobre el origen de los vocablos deuda ecológica y de pasivo ambiental.

En la revisión bibliométrica se detectó que los Países que han publicado más investigaciones sobre el tema son: Ecuador, México, España, Chile, Argentina, Canadá, Cuba, Venezuela, Colombia, El Salvador, Costa Rica desde el año 1970 y con más relevancia en los años 2000 , centrando el $80 \%$ en el enfoque sobre deuda ecológica y deuda externa, lo cual se constituyó en la base para la estructura del documento monográfico, soporte de este artículo.

\section{ANTECEDENTES AL ENFOQUE DE LA DEUDA ECOLÓGICA}

El ser humano por su carácter natural y su dependencia absoluta de la naturaleza para su supervivencia, ha hecho uso de ella desde su origen, no solo para satisfacer las necesidades de vida, sino, para acumular en busca de poder, conllevando a inevitables consecuencias, que hoy son motivo de preocupación mundial. Sin embargo, en los inicios del hombre en la tierra no se contemplaban efectos negativos de sus acciones en el entorno natural, por la capacidad de la naturaleza para autorregularse y recuperarse, con una baja carga y el hombre actuaba como parte de la cadena alimentaria de equilibrio, por lo que no se hacían visibles los impactos.

En efecto, las primeras comunidades establecían una estrecha relación de uso y respeto por la naturaleza porque de ella obtenían justamente lo que necesitaban, antes de establecerse en determinadas regiones, simplemente tomaban lo que la tierra les brindaba, pero ya sedentarios logran someter la tierra y su contenido, con la explotación mediante actividades de siembra y domesticación de animales, lo que fue evolucionando, hasta alcanzar la racionalidad tener y acumular, afectando la capacidad natural de la tierra para autorregularse. De ahí, que las áreas que sirvieron de asentamiento de las primeras 
civilizaciones se hayan convertido en zonas desérticas, inclusive, la vasta región donde se estima existió el "Jardín del Edén", que para algunos investigadores pudo ser Irak o Jerusalén, o parte del Golfo Pérsico o el Medio oriente. (Gracia, 2012)

Al revisar la historia de la humanidad, merece atención especial el reconocimiento de la relación del hombre con la naturaleza en el periodo moderno, en el cual es trascendental el descubrimiento de América, por constituir la base de nuestras culturas y dejar en evidencia a los pueblos europeos conquistadores como saqueadores de la naturaleza con la explotación de minerales preciosos, con un afán mercantilistas. De ahí, que se lanzaran en busca de nuevos territorios para invadirlos y apoderarse de lo que significara riqueza, convirtiéndose en un verdadero "saqueo" en el que se apoderaban ilegítimamente de las tierras de los indígenas y elementos (activos y bienes naturales) hasta destruir su hábitat, de la mano con la biopiratería, causante de gran daño (deuda ecológica), (Shiva, 2001).

Desde ese momento se encuentra lo que se llamaría hasta hoy el intercambio comercial totalmente desigual. "Ni los países compradores pagaban el precio real de los bienes comprados, ni las naciones vendedoras cobraban todos los valores incorporados en el producto vendido." (Lanuza, Moreno, \& Larin, 2007)

En el caso de América Latina la colonización, no solo implico la destrucción del ecosistema, sino, que causo un daño social enorme al tomarse a los indígenas como esclavos y obligarlos a cambiar su cultura, y que dejaran de creer en los dioses de la naturaleza; también cultivan las semillas de sus tierras en las tierras conquistadas, iniciando así el monocultivo y la mono producción, causando daños a la naturaleza, al afectar la diversidad de tierras y degradación de los suelos (Cabrera \& Zuaznabar, 2010)

Años después, el daño a la naturaleza se intensifica con la revolución industrial en el siglo XVIII (Albert, 2004), originando el principio del fin, ya que la destrucción de la naturaleza comenzó a darse de forma masiva, con el descubrimiento de combustibles y explotación intensiva de los recursos minerales de la tierra, con lo cual se empezó a ver afectada la calidad del aire, del agua y por supuesto la calidad de vida humana. Las grandes industrias se convierten en las responsables del daño masivo, pero ninguna retribuye a recuperar el daño ocasionado. De hecho, con la revolución industrial se inicia la aceleración de la producción en la industria mundial, con aumento en la riqueza de algunas naciones que le apuntaron a la industrialización, creando una gran brecha entre países ricos y pobres, con el progreso a la producción a gran escala. Con esta forma de producción se crea en la humanidad la cultura de consumismo, al despertar deseos, por lo que se compra sin necesitar, aumentando los desechos con problemas de disposición, encontrando hoy una isla de basura en el océano pacifico, lixiviados contaminando fuentes subterráneas, emisión de metano y otros gases causantes del cambio climático.

Resultado de las prácticas de acumulación de riqueza, las industrias han provocado el uso irresponsable de la naturaleza, hasta causar el calentamiento global con la quema de combustibles fósiles, cambios de uso del suelo, la minería, la ampliación de las fronteras agrícolas y ganaderas, entre otros, originando la deforestación, con efectos ambientales como derretimiento de los casquetes polares, la subida del nivel del mar y la reducción del agua potable (Alonso, 2013). 
Lo anterior, no significa que la revolución industrial haya sido error para el mundo, pues permitió progreso y desarrollo tecnológico por la búsqueda de la eficiencia con la simplificación de procesos productivos de bienes para satisfacer las necesidades de la población, desconociendo las consecuencias que acarrearía la implementación y avance en tecnologías que desplazan el trabajo humano y deterioran el ambiente. Situación que es atribuible a la racionalidad equivocada del pensamiento liberal clásico, que excluye de sus fundamentos los bienes libres y aparentemente ilimitados (naturaleza), centrando su enfoque a la acumulación de riqueza como factores de bienestar y desarrollo, lo que convirtió al hombre en un ser codicioso, adicto a la riqueza material, sin importar el daño que ocasiona al medio que le rodea y la humanidad.

"La destrucción de hábitat está a menudo vinculada a la codicia y el materialismo del mundo desarrollado" - Dian Fossey.

En la historia ecológica se distinguen dos corrientes contrapuestas, como lo plantea González de Molina (2000), debido a que la primera quiere analizar como el hombre ha asumido la evolución de la naturaleza, sabiendo que él es el único ser pensante que puede hacer de ella lo que quiera para satisfacer sus necesidades y sin importar las consecuencias que le genere y, la segunda en entender el contexto ambiental de la actividad humana colocando por encima lo que la naturaleza le ha brindado para desarrollarse. Para el autor estas dos corrientes son la historia de la naturaleza o de las externalidades negativas del hombre. (Gonzalez de Molina , 2000)

\section{PENSAMIENTOS FILOSÓFICOS SOBRE EL DAÑO AMBIENTAL}

\section{¿Antropocentrismo o Biocentrismo?}

Desde la antigua Grecia, los filósofos se han cuestionado sobre la conducta del ser humano y su esencia, sin embargo, para algunos la importancia recaía en la naturaleza y para otros en el hombre, originando dos corrientes filosóficas, el antropocentrismo radical y la ecofilosofía biologista.

Hablar de antropocentrismo hace referencia a aquella concepción filosófica que considera al hombre como el centro de todas las cosas, corriente defendida por filósofos como Marx quien decía que "el mundo existe como sustrato de la naturaleza, que el ser humano está en condiciones y en la obligación de transformar mediante el trabajo y las relaciones de producción." (Marx, 1973). Esta frase de Marx no está del todo mal, puesto que el hombre debía evolucionar y utilizar los recursos naturales para la satisfacción de sus necesidades, el problema radica en cómo se le retribuye o al menos preservando y no ser simplemente un depredador. Otro filósofo defensor del antropocentrismo fue Kant, ya que su filosofía buscaba que se fortaleciera la autonomía del hombre y re-afianzó esta concepción como fundamento de toda posterior filosofía y forma de vivir. (Lerussi, 2014). Pero ¿cómo puede el hombre ser autónomo, si depende de la naturaleza para subsistir?

Para Figueroa "el antropocentrismo de corte utilitarista o radical debe ser cuestionado desde el punto de vista ético no sólo por su irresponsabilidad frente al ecosistema global, sino por el afán de consumo y usufructo sin la autocrítica que ello supone." (Figueroa, 2012) 
Por otro lado, se tiene el Biocentrismo que expone la vida como centro, soportado en la teoría moral, todo ser vivo merece respeto. Surge en los años 70 siendo uno de los filósofos defensores de este pensamiento Leopold quien considera a la especie humana, un animal más, según él, la crisis ambiental surgió en la actividad económica sin una base ética. Expone que se abandonó la relación ser humano naturaleza y que la Tierra ha sido considerada como una esclava, las relaciones con ella han sido de explotación económica utilitarias, con privilegios exclusivos para el ser humano (Leopold, 1970).

Si bien, las actitudes humanas se han conducido en un antropocentrismo radical con nefastos efectos hasta hacer incierto el futuro del planeta, asumir una postura moderada del antropocentrismo que establezca al hombre como el receptor de todas las consecuencias de los procesos que se realicen en la tierra y no como el dominante absoluto conduce a la apropiación de una visión biocentrista. Realmente, esta es una concepción más completa y menos egoísta, que lía el bienestar de todo ser vivo sin exclusión, puesto que, la ruptura entre la relación del hombre, con la naturaleza, al sentirse como supremo, es la causante de los problemas ambientales presentes, lo cual puede llevar a la extinción del propio ser humano.

Un reconocimiento de los procesos históricos del ser humano en su relación con la naturaleza, en el marco de actitudes identificadas en las diferentes corrientes filosóficas y bajo un enfoque antropocéntrico permite reconocer, que es este el que ha conllevado al agotamiento de los bienes y servicios naturales, fundamentales para la vida, siendo responsabilidad del hombre desde sus diferentes roles, asegurar la disponibilidad de los beneficios naturales. De ahí, se desprende el interés por estudiar la relación del hombre con el agotamiento de las bases naturales del desarrollo de toda sociedad, lo que ha permitido concepciones como la deuda ecológica, huella ecológica, pasivos ambientales, sostenibilidad ambiental entre muchos otros, siendo motivo de análisis en los siguientes epígrafes el tema de deuda ecológica.

\section{ALGUNAS DEFINICIONES DE DEUDA ECOLÓGICA}

A principios de los 90 las organizaciones académicas comenzaron a investigar sobre deuda ecológica. Uno de los primeros en detallar el concepto de esta, fue la organización Acción Ecológica citada por Azamar \& Carrillo definiéndola así:

"La Deuda Social-Ecológica es la deuda acumulada, histórica y actual, que tienen básicamente los países industrializados del Norte, sus instituciones y corporaciones, con los pueblos y países del Sur por el saqueo y usufructo de sus recursos naturales, la explotación y empobrecimiento de sus pueblos, y la destrucción, devastación y contaminación sistemática de su patrimonio natural y fuentes de sustento. Es también la responsabilidad de los países industrializados por la destrucción paulatina del planeta, el deterioro de la capa de ozono, la contaminación de la atmósfera, la generación del efecto invernadero, como resultado de su modelo de "desarrollo" y sus patrones de producción y consumo." (Azamar \& Carrillo, 2017, 403) 
De igual manera para Paredis y otros (2004), la deuda ecológica es de carácter histórico, consecuencia del daño ecológico en el tiempo de un país sobre otros, resultado del modelo de producción y consumo que conduce al uso y explotación de ecosistemas, sus bienes y servicios ambientales, "a expensas de los derechos equitativos de otros países o individuos" (Paredis, et al, 2004).

Así mismo, para Balanya y Ortega la deuda ecológica va más allá de la explotación moderna, pues esta se origina según ellos desde la época colonial, creciendo paulatinamente hasta el día de hoy, evidenciada en aspectos como: pasivos ambientales por actividades de extracción de los recursos no renovables (minería), con baja retribución y desconocimiento de impactos socioambientales, con afectación directa del desarrollo de los pueblos. (Balanyá \& Ortega, 2005)

Russi y otros (2003), aunque mantienen la línea del origen histórico de la deuda ecológica, establecen la colonia como punto de partida, aunque centran su definición en las dinámicas de explotación moderna, definiéndola como:

"La deuda contraída por los países industrializados con los demás países a causa de expolio histórico y presente de los recursos naturales, los impactos ambientales exportados y la libre utilización del espacio ambiental global para depositar sus recursos. La deuda ecológica se origina en la época colonial y se ha incrementado hasta la actualidad con: la deuda de carbono, la biopiratería, los pasivos ambientales y la exportación de recursos tóxicos, originados en los países industrializados y depositado en los países pobres." (Russi, et al 2003).

Definición que coincide con la realizada anteriormente por Donoso (2000), al referirse que esta se ha estado acumulando por la explotación de los recursos naturales por parte de los países del Norte (Industrializados) en los países del Tercer mundo, con pagos subvaluados y con efectos ambientales negativos por gratuidad en explotación de recursos genéticos, ocupación del espacio ambiental con el depósito de los gases de efecto invernadero u otros residuos acumulados. (Donoso, 2000).

En ese mismo orden de concepciones la deuda ecológica, se refiere a la responsabilidad de los llamados países del norte por las explotaciones efectuadas en los países del sur en el suministro de materias primas y recursos energéticos, así como una desigual emisión de $\mathrm{CO}_{2}$, generando una colosal deuda ecológica sin compensar los daños (Barcena, Lago, \& Villalba, 2009). Por su parte Martínez señala que la deuda ecológica surge de los países del Norte con la acumulación de daños ambientales generados en la explotación de bienes naturales en países del sur para proveerse, sin que estos sean compensados con los precios comerciales y, menos aún los impactos ambientales resultantes en los procesos productivos y contaminación a escala global. (Martínez, 2005)

A su vez, Aguilón y otros (2004), opinan que hablar de deuda ecológica es hacer exigible una justicia tanto ambiental, como social y económica; es razonar en torno a la riqueza y la pobreza, con reconocimiento de sus responsables y, converger en contra de la impunidad, en defensa de la destrucción de la vida y la cultura de los pueblos empobrecidos por los 
países industrializados. (Aguillon, et al, 2004). En este mismo orden de ideas Bullard (2010) manifiesta que el concepto de "deuda ecológica histórica" permite "plantear la cuestión central de la responsabilidad histórica y de quién debe a quién y para qué." (Bullard, 2010: 17). Por lo que la finalidad de la deuda ecológica es alcanzar el reconocimiento del daño que han provocado los países industrializados en los no industrializados, con sus sistemas de producción, por lo que el reconocimiento del daño debe exigir la nulidad de los altos interese de la deuda externa. (Azamar \& Carrillo, 2017)

Martínez y Oliveras (2003), señalan que en la deuda ecológica:

\begin{abstract}
"Se vinculan con los costos de reproducción o manejo sostenible de recursos renovables exportados, la reposición de los nutrientes incorporados en las exportaciones agrarias, los costos de reparación de los daños locales como daños a la salud por el uso de agroquímicos prohibidos en sus países de origen, disminución productiva por sobreexplotación, contaminación con mercurio, relaves de minas, costos por la indisponibilidad futura de recursos no renovables como el petróleo o la biodiversidad. Todos estos costos no son considerados en el precio, por lo que terminan siendo pagados por el país exportador y sus generaciones futuras". (Martínez \& Oliveras, 2003)
\end{abstract}

En general se evidencia que la deuda ecológica, se basa en concepciones y que tienen su origen en un discurso político, manteniendo posturas muy similares, ya que más que tener definiciones de origen epistemológico y científico, puesto que, aunque los diferentes autores citados lo expresan de manera diferente, poco se han distanciado del concepto inicial.

Por lo tanto, de las concepciones presentadas de deuda ecológica, se puede asumir que esta se establece entre naciones, consecuencia de la misma inequidad en los procesos de industrialización mundial bajo un enfoque de desarrollo de países del centro y la periferia expuesto por Sunkel y Paz (1999) en su libro El subdesarrollo latinoamericano y la teoría del desarrollo, en lo cual los países no industrializados aportan las materias primas mediante la explotación de la naturaleza y los países industrializados lo transforman siendo responsables de altos consumos de energía, generación de bienes que convierten a los bienes de la naturaleza en no biodegradables.

También se ha hablado sobre una deuda climática, la cual según Le Quang, M. (2015) "es parte de la deuda ecológica, se descompone principalmente en tres tipos de deuda: la deuda de emisión, es decir la contaminación con los gases a efectos invernaderos; la deuda de desarrollo, partiendo del principio de que los países del Sur tienen derecho a las mismas posibilidades de desarrollo económico que los países del Norte y entonces deben poder tener acceso a las nuevas tecnologías limpias para no aumentar la contaminación; y la deuda de adaptación".

\title{
LA DEUDA ECOLÓGICA EN LA DEUDA EXTERNA
}

La deuda ecológica se dio a conocer con los diferentes tratados y convenios internacionales, realizados desde los años 90, el Instituto de Ecología Política de Chile público un documento 
afirmando que la producción de clorofluorocarbonos (CFC) de los países industrializados acabarían con la capa de ozono, ocasionando daños en la fauna y la flora hasta acabar con la salud de los seres humanos, señalando todas estas actitudes por parte de estos países como una "Deuda ecológica", con el fin de resarcir el daño causado.

En Rio de Janeiro en el año 1992 se aprueba un documento marco entre grupos ecologistas en el cual se relaciona la Deuda externa con la deuda ecológica. En ese documento se hablaba sobre el comercio de materias primas, las que estaban siendo mal pagado por los países del Norte y sobre la ocupación desproporcionada del espacio ambiental. Es por eso que la deuda ecológica busca invertir los papeles, al considerar deudor a todos los ciudadanos y empresas de los países ricos y como acreedor a los habitantes de los países pobres, por el hecho de acabar con sus recursos naturales.

"La deuda externa de países pobres se ha convertido en elemento de control, pero no ocurre lo mismo con la deuda ecológica. La tierra de los pobres del Sur es rica y poco contaminada, pero el acceso a la propiedad de bienes y recursos para satisfacer sus necesidades vitales, les está vedado por un sistema de relaciones comerciales y propiedad estructuralmente perverso". (Martínez et al, 2015)

En la cumbre de Rio de Janeiro en 1992, Fidel Castro expreso: "Hágase más racional la vida humana. Aplíquese un orden económico internacional justo. Utilícese toda la ciencia necesaria para un desarrollo sostenido sin contaminación. Páguese la deuda ecológica y no la deuda externa. Desaparezca el hambre y no el hombre" lo cual dio aún más importancia a la deuda ecológica. (Rodríguez, Bustamante, \& Jean- Claude, 2011). Sin embargo, en la cumbre de Rio, "la deuda externa se destacó por su ausencia, como también estuvo ausente la deuda ecológica del Norte para con el Sur, tan vehementemente defendida por actores tan distintos como las ONGs, el BID, la CEPAL y otras instituciones regionales". No se llegó a ninguna conclusión sobre esta, pero al menos se dio a conocer y tuvo relevancia (Guimaraes, 1992).

En las campañas de Jubileo 2000 y Jubileo Sur contra la Deuda externa, se ha impulsado el reconocimiento de la deuda ecológica, así mismo sus activistas han precisado que la deuda ecológica es mayor que la deuda externa, puesto que, en la deuda ecológica es incierta la recuperación al no poderse resarcir el daño que se le causa al planeta, en cambio la deuda externa son recursos económicos que bien o mal se pueden cancelar. De ahí, la importancia de precisar quién es el responsable de todos los impactos ambientales, teniendo en cuenta que en todo país hay un mercado que busca pasar por encima de todos, sin importar el daño que pueda causar. Estas consecuencias son entendidas como externalidades, es decir, los impactos ambientales. Un ejemplo de estas externalidades es la contaminación que se produce lejos de los puntos de emisión y consumo y el agotamiento de recursos que afectará a las generaciones futuras (Russi, et al, 2003), sobre lo cual Martínez (1998) manifiesta que los economistas llaman externalidades "los impactos negativos no reconocidos por los precios del mercado"

Según Hinkelammert, citado por Pirela (2009): aunque la deuda ecológica no es pagada en términos financieros, el pago del daño a la naturaleza y el ambiente se paga con 
enfermedades y la muerte de segmentos poblacionales que son sometidas a la pobreza por el sistema de inequidad económica que prevalece en el mundo de economía liberal, dejándolas sin acceso a sistema de salud alguno, e incluso llegando a la indigencia (Pirela, 2009)

Según Tibán Guala, L. (2004). "Todo este invento de la sustentabilidad viene de los países del Norte para reparar los desastres ecológicos causados por sus empresas en nuestro país. Es decir, ellos dañan el ambiente mundial y quieren que nosotros arreglemos, pero, ¿el Norte estará consciente que nos debe una deuda ecológica al mundo entero? Creo que no, porque mientras aquí seguimos pensando en conservar el ambiente y el ecosistema, allá siguen inventando cosas para destruir el mundo a través de la riqueza".

Por tanto, es importante que los países industrializados asuman su responsabilidad y compensen la deuda ecológica con la deuda externa. Pero para elloes importantecuestionar cuál es el valor actual de la deuda externa que tienen los países no industrializados con los países industrializados, ya que durante años el gobierno se ha esforzado en pagar esta deuda y se ve que este valor no disminuye significativamente.

¿De qué manera ha pagado el gobierno la deuda externa? Día a día los países en desarrollo se esfuerzan en cancelar aquella deuda contraída en el pasado que hoy se le atribuye al presente y afectará al futuro. Pero ¿por qué se habla del futuro? Esta relación es importante aclararla ya que en un principio esta deuda fue contraída por los gobiernos pasados, ha sido cancelada por los gobiernos del presente por medio de la exportación de bienes y productos consumibles a bajo costo y está afectando las generaciones futuras, porque con el fin de cancelar a toda costa, los países han exportado y extraído más de lo que se debe y han olvidado esa relación ancestral con la madre naturaleza, pero esta no lo olvida ya que hoy en día se está viendo afectada significativamente, con efectos preocupantes a la humanidad.

\section{VALORACIÓN DE LA DEUDA ECOLÓGICA}

Ya se ha planteado que los países industrializados tienen una deuda con los países no industrializados a la cual llamamos deuda ecológica, pero el debate siempre ha sido la cuantificación y valoración de esta deuda en dinero, lo cual no se ha logrado definir aun, puesto que la valoración de la naturaleza y sus alteraciones está en proceso de construcción. Autores como Aguilón y otros (2004), en su publicación, ¡No más saqueo y destrucción!, afirman que la deuda ecológica es difícil de monetizar puesto que no hay valores monetarios para valorar la perdida de suelos, el envenenamiento, los deslaves de lodo, la sedimentación, las inundaciones, los hogares destruidos, las comunidades destrozadas y las culturas erradicadas. (Aguillon, et. al, 2004)

Según Barcena \& Lago "es prácticamente imposible valorizar el daño ecológico en Latinoamérica que deriva de las actividades extractivas realizadas desde la colonia, por lo que es complejo generar entre las naciones del centro una conciencia de reconocimiento, ya que no existe un respaldo adecuado y eficaz para demostrar el perjuicio en términos económicos." (Barcena, Lago, \& Villalba, 2009) 
Por lo tanto para Azamar \& Carrillo se hace necesario "realizar un seguimiento estricto de la deuda ecológica que permita identificar los impactos económicos-ambientales más actuales, pero aun así no se tienen métodos precisos para comprobar una relación entre el extractivismo anterior a los tratados de libre comercio modernos y los problemas ecológicos actuales, ya se deben considerar las características de los acuerdos comerciales vigentes y anteriores entre las naciones del norte y del sur." (Azamar \& Carrillo, 2017)

"Intentar comparar la deuda ecológica con su contraparte financiera presenta una serie de dilemas. En tanto que las compañías aseguradoras pretenden fijar un valor monetario a la vida humana, el valor intrínseco de un ser humano o de la biosfera como soporte de toda manifestación de vida, humana o no humana, jamás podrá reducirse a meros dólares." (Dillon, 2000). Sin embargo, Martínez (1998), propone un modelo de valoración de la deuda ecológica basado en:

"Si desde el Sur una parte de la opinión pública, y al menos algunos gobiernos, adoptaran la perspectiva del "ecologismo popular", entonces se podría avanzar en el reclamo al Norte de la Deuda Ecológica. No se trata de cambiar Deuda Externa por Naturaleza (como ha ocurrido en algunos casos que en conjunto no han supuesto en términos financieros ni el uno por ciento de la Deuda Externa de la América Latina), sino al contrario, dar por cancelada la Deuda Externa que se debe al Norte a cuenta de la Deuda Ecológica que el Norte debe al Sur. ¿Cuánto debe exactamente? No creo que el argumento dependa de una cuantificación exacta, que es por otro lado imposible (por ejemplo, al exportar madera del bosque tropical húmedo, se ha perdido y se pierde biodiversidad que no está tan siquiera inventariada, mucho menos es pues valorable en dinero). Pero, aunque no pueda hacerse una cuantificación exacta, sí que es necesario establecer los rubros principales y unos ciertos órdenes de magnitud, para impulsar la discusión." (Martínez, 1998)

De acuerdo a lo anterior, para Martínez la deuda ecológica tendría viabilidad desde la perspectiva del ecologismo popular, basado en que la comunidad ejerza la defensa de los recursos naturales de la depredación del mercado, uniéndose el pueblo en movimientos de resistencia que luchan para impedir la privatización de la propiedad comunal e, impedir las llamadas externalidades o impactos negativos ambientales y sociales no recogidos por los precios del mercado para así, poder valorar la deuda, lo cual no es una concepción muy clara a la hora de establecer valores, pues la deuda ecológica encarna aspectos como la plusvalía, no solo por apropiación del valor generado por el capital humano, como lo plantea Marx, sino apropiación del valor que genera la naturaleza de manera intrínseca y que según Mantilla (2018) se le desconoce y se apropia por el sistema de explotación del sector primario, siendo la naturaleza generadora de valor de manera autónoma, puesto que el capital humano y el capital tecnológico o medios de trabajo, solo adecuan la disposición para facilitar y efectuar su explotación.

Para Mantilla (2005) "La valoración o determinación de los costos ambientales, implica el reconocimiento de los cambios en las condiciones y las características de los elementos de la naturaleza y, el valor relacional que esto implica en referencia a los efectos sobre el 
hombre, su contexto económico, social y sus ecosistemas. De hecho, las cosas tienen valor en la medida que le reportan algún efecto positivo o negativo en el bienestar humano, por lo que los elementos que conforman la naturaleza adquieren la categoría de bienes tangibles e intangibles (Bienes y Servicios Ambientales -BSA) y su deterioro define el Costo Ambiental, el cual define el valor que precisa cualquier deuda con la sociedad afectada por su deterioro ambiental (Mantilla, López \& Verjel, 2005).

Por su parte, otra apreciación de Martínez y Oliveres (2003) la valoración de la deuda hace necesario tener en cuenta unos costos planteados como por ejemplo, los costos de producción o manejo sustentable de los recursos naturales renovables exportados (que nunca fueron pagados), los costos actualizados por perdida de la disponibilidad futura de los recursos no renovables destruidos o usufructuados, los costos de reparación no pagados por daños locales causados por las exportaciones o, de no existir reparación posible, el importe actualizado de los daños, los costos de reparación no pagados de las consecuencias de la importación de residuos tóxicos, sólidos o líquidos (incluidos los efectos nocivos sobre la salud humana) y el importe (tampoco pagado hasta ahora) de la información y conocimiento sobre recursos genéticos robados o cedidos (por las culturas aborígenes), siempre que haya habido un aprovechamiento comercial de esta información o a lo que llamamos biopiratería. (Martínez Alier \& Oliveres, 2003)

Así mismo, según Aguilón y otros, Esperanza Martínez en su publicación expresa que no se puede poner precio a la vida, sin embargo, si se puede y se debe establecer sanciones, civiles y penales a quienes la destruyen. No se puede poner precio a un rio muerto, a un bosque talado, pero si se puede calcular cuánto costaría sustituir los servicios que brindaban. Para explicar esta valoración ella establece el ejemplo de la deuda ecológica de Texaco con Ecuador; esta compañía petrolera estadounidense genero consecuencias como contaminación y destrucción de grandes extensiones de selva en la región amazónica, el exterminio de pueblos indígenas y el empobrecimiento casi generalizado de la región. (Aguillon, et. al., 2004)

Lo que se hizo para valorar esta deuda fue identificar los rubros de daños más significativos, como los rubros de: Deuda por petróleo no pagado, por derrames de crudo, por limpieza de pantanos, por quema de gas, por peces muertos y agua usada, por arena usada en plataformas y carreteras, por deforestación y pérdida de biodiversidad, por madera usada en plataformas y carreteras, por animales silvestres, por la salinización de los ríos por enfermedad, por trabajo mal pagado, por genocidio, por endeudamiento externo y por carbono producido. Seguidamente, se analiza cada rubro y, con base en investigaciones en fuentes confiables se determina cuanto valdría reversar el daño producido. (Aguillon, y otros, 2004)

Por ejemplo, en el caso de la desalinización del agua, se sabe que de algún modo con maquinaria especializada se puede lograr obtener agua potable pero no totalmente, por lo tanto, se debería reparar a la población afectada llevándoles agua potable, y este se calcularía con el precio de mercado del litro de agua. Pero en el caso de la deuda por salud y genocidio, así como de animales silvestres seria incalculable la deuda por qué no se puede reversar el daño causado por una muerte o lo que se haría serian estimaciones basadas en 
otros casos de genocidio como por ejemplo la forma en que los alemanes compensaron a los judíos por el genocidio nazi. (Aguillon, y otros, 2004)

Por su parte, Mantilla (2006), expresa que si se revisa con cuidado el origen del conjunto de bienes que se intercambian en una nación, es relevante el papel de los elementos de la naturaleza, sin embargo, el valor de estos bienes objeto de explotación, no definen su valor en el sistema de precios, porque los beneficios económicos obtenidos, son solo reflejo parcial del aporte al bienestar humano, puesto que son los ecosistemas los que contextualizan la vida en el planeta, los que rigen y perpetúan la misma con los equilibrios resultantes en la dinámica sistémica de interrelación natural. (Mantilla, 2006)

Por otro lado, Kapp, manifiesta que se podría obtener un cálculo monetario preciso para la deuda, pero al ubicar ese valor y si se aplica un índice de descuento para futuras utilidades o incapacidades que expresen su valor actual capitalizado, no se sale del dilema de una elección, ni del hecho que se arriesga la salud y sobrevivencia humana, es por eso que el autor considera que medir los costos y beneficios sociales en valores, está destinado al fracaso. (Kapp, 1970)

Ante la diversidad y falta de un criterio unificado, Dillon (2000), piensa que "Todo intento de calcular la deuda ecológica debe partir de otras premisas: el valor inestimable de toda vida y el reconocimiento de la economía humana como un subsistema dentro del gran ecosistema, tiene un valor inmensurable." (Dillon, 2000)

Es por esto que, se afirma que la deuda ecológica se puede cancelar únicamente cuando los pueblos han ganado control sobre los recursos, los medios de producción y cuando la utilización de estos no sea en función de lucro, sino de la satisfacción de las necesidades de la población, aunque al ser conscientes, esta deuda no tendría un valor monetario, puesto que los cálculos son estimados, en muchos casos de extrema subjetividad. Sin embargo, la valoración de la deuda ecología de Texaco con Ecuador según Martínez sumo 709.222 millones 667 mil dólares, es decir 51 veces la deuda externa de Ecuador y eso que los cálculos son inexactos, por lo que se puede confirmar que los países del norte deben a los países del sur. (Aguilón, et. al., 2004)

En definitiva, el debate que pareciera no tener fin es el de valorar la deuda ecológica que los países del Norte deben a los del Sur, ya que existen muchas contradicciones. Para Zacher (1992) el factor más importante para valorar la deuda son las "externalidades internacionales negativas" resultantes de actividades que dentro de un país o Estado tienen efectos negativos en otros, viendo reflejados estos efectos en temas como la salud, bienestar de la gente. Así también, esta valoración de externalidades ayudará a que las empresas transnacionales valoren sus pasivos ambientales, como elemento importante para el cálculo global de esa deuda. (Zacher, 1992)

Para finalizar, resulta importante que, para poder conservar el planeta, se deban establecer los costos de los daños ambientales, como expresión de la deuda ecológica y, que permita fijar responsabilidades, en la recuperación de los daños causados al ambiente y, que el hombre deje de sobrexplotar la naturaleza, que entienda que es un préstamo de nuestra 
descendencia. Es indudable que los daños son difíciles de remediar e incluso imposible, por lo que la solución no está en definir cualquier valor como una aparente deuda ecológica, por ello se debe trabajar una alternativa que evite deterioros irreparables, por lo que los gobiernos deben implementar políticas fiscales ambientales agresivas, para obtener el pago de daños o desestimularlos.

Sin embargo, algunos economistas coinciden en afirmar que el impuesto ambiental conlleva a la pérdida de competitividad de las empresas, cunado son internalizados los impuestos y costos ambientales en la definición de los costos de producción, por ende, en el valor del producto o servicio.

\section{¿CÓMO SE PUEDE PAGAR LA DEUDA ECOLÓGICA?}

Según Geneviève Azam: "La deuda ecológica de los países industrializados no es una deuda financiera, que supone una evaluación económica de los bienes ambientales, sino, una deuda política que otorga la responsabilidad primaria a los países endeudados de cambiar de trayectoria. Las transferencias financieras son necesarias para reducir la desigualdad entre sociedades, pero en ningún caso pagarán la deuda ecológica, librando a los países industrializados del daño a ellos mismos y a otros". (Azam, 2010: 185)

Una vez valorada la deuda ecológica desde las propuestas planteadas, se debe pensar en cómo cancelase, en lo cual Martínez Alier, plantea que se podría realizar mediante la creación de impuestos ecológicos, como lo pensaba hacer Estados Unidos para cumplir con los objetivos de la cumbre de Rio de 1992. El impuesto a crear se llamaría BTU-tax, cuyo hecho generador es el uso de energía de combustibles fósiles y, se haría para encarecer su precio y disminuir su demanda, con efecto en la reducción en las emisiones de dióxido de carbono; sin embargo, no se pudo imponer por la aparente pérdida de competitividad. (Martínez Alier, 1998)

Por su parte, quienes opinan que los daños causados se deben reconocer, por medio de indicadores como la capacidad de carga, el espacio ambiental y la huella ecológica, implementando a su vez políticas ambientales y económicas que impidan generar una nueva deuda y se busque reparar los daños sociales y ambientales, aunque todo no es reparable al haber daños irreversibles. Se deben reconocer monetariamente los daños, que viabilicen compensar la deuda externa con la deuda ecológica. (Barcena, Lago, \& Villalba, 2009)

Se debe construir un modelo teórico de políticas fiscales ambientales que amplíe el sistema existente, teniendo en cuenta el destino de ese impuesto, pues debe ser invertido en la reparación de los daños ambientales (Henríquez et al 2009). Para Martínez (2003), se deberían reforzar las políticas empresariales de modo que haya una mayor exigencia en cuanto a los seguros ambientales para los lugares de mayor fragilidad ecológica (Martínez, \& Acción Ecológica 2003), mientras Pérez, y otros (1996) hablan sobre el Canje de Deuda por Naturaleza y/o desarrollo, el cual describen como "un mecanismo financiero que involucra la compra o condonación de la deuda externa, siempre que esta sea convertida en moneda nacional y usada para financiar proyectos de desarrollo (Pérez, Umaña, 1996). 
Un aspecto clave de esta transacción es la voluntad del banco o país acreedor, de negociar la deuda a un precio menor que el nominal".

Si bien, es complejo lograr el reconocimiento de la deuda ecológica, no obstante, las diferentes definiciones expuestas, el hablar de cómo pagarla pareciera más un discurso en busca de adeptos que un enfoque técnico y científico que conlleve a resarcir los daños con la identificación de los responsables. Por un lado, se debe separar el daño causado por los actores sociales residentes del país afectado, que muchos consideran base de los pasivos ambientales, de los daños de agentes económicos del exterior y, por otro lado, se debe entender que toda contaminación o alteración de la naturaleza genera un costo ambiental, el cual se debe determinar con base en un sistema contable apropiado con uso de métodos de valoración ambiental, que aproximen el valor de las condiciones ambientales y sus cambios.

$\mathrm{Al}$ respecto, el costo ambiental se entiende como el valor de la sumatoria de los efectos sociales, económicos y ambientales que se presentan al afectar las condiciones de la naturaleza y, no simplemente como valor de recuperación o reposición del elemento o ecosistema afectado, pues de hecho, la naturaleza se entiende como contaminada en la relación con el bienestar humano y su contexto, mas no en la alteración simplemente de sus elementos en sí; por lo que, el costo corresponde al valor de los efectos en las personas, la economía familiar y regional, determinándose en el valor de la reposición o recuperación de la naturaleza y, tratamiento de los efectos en la salud, más valor del tiempo de incapacidad, reducción de la producción regional por incapacidades y efectos en ríos, ecosistemas y, capacidad productiva del suelo, entre otros. (Mantilla, Vejel \& López, 2005)

\section{INDICADORES EN LA DETERMINACIÓN DE LA DEUDA ECOLÓGICA}

El Instituto de Ecología Política -IEP (2001) pionero de la expresión deuda ecológica, publicó el trabajo realizado por el Global Footprint Network (GFN), el estudio revela que "la tierra entra en -Deuda ecológica- al consumir su presupuesto de recursos", en el cual revela que el mundo agota los suministros naturales (tierra, bosques y el mar), que se están "consumiendo sus ahorros", causa de acumulación de dióxido de carbono, lo que determina la huella ecológica que la humanidad deja cada año. Según el presidente de la GFN (Mathis Wackernagel), creador de la expresión "huella ecológica", manifiesta que la presión de los seres humanos sobre los recursos del planeta es "como gastar el salario anual tres meses antes de que termine el año, y consumiendo sus ahorros". La situación es tan grave que, para satisfacer las necesidades de recursos naturales del mundo, se necesitaría planeta y medio, cifra que no disminuye, sino aumenta paulatinamente. (IEP, 2011)

A su vez, el estudio reveló que los países industrializados están explotando intensivamente la naturaleza, por tanto, deberían realizar inversiones en economía verde, para afrontar la crisis económica y la deuda ecológica. La no concientización sobre el uso de los recursos naturales puede traer resultados como falta de agua, extinción de las especies y colapso de la pesca, es por eso que hoy se afronta la realidad de haber gastado durante años más de lo que se debía. "Si vamos a mantener unas sociedades estables, ya no podemos sostener 
esta amplia brecha presupuestaria entre lo que la naturaleza puede suministrar y lo que se requiere en materia de infraestructura y la economía, Mathis Wackernagel" (IEP, 2011)

A causa de los daños causados al ambiente se plantea la necesidad del uso de indicadores sobre deuda ecológica como la Biocapacidad o Espacio Ambiental, Apropiación Humana de la Producción Primaria Neta (HANNP), El Energy Return on Investment EROI, el MIPS o Mochila Ecológica y la Huella ecológica. Es la huella ecológica el indicador más posicionado, desde su creación por Mathis Wackernagel y William Rees (2008), definido como "el área o territorio ecológicamente productivo (cultivos, pastos, bosques o ecosistema acuático) necesaria para producir los recursos utilizados y para asimilar los residuos producidos por una población definida con un nivel de vida específico indefinidamente, donde sea que se encuentre esta área" (Wackernagel \& Rees, 2008). De otra manera es un indicador biofísico que permite estimar los requerimientos en términos de consumo de recursos y la asimilación de desechos de una determinada población y economía, expresados en áreas de suelo productivo, permite determinar la dependencia que tiene la población de una ciudad, región o país, de las importaciones de recursos y su capacidad de asimilación de desechos disponibles. (Tobasura, 2008)

El cálculo de la huella ecológica se basa en la estimación de la extensión de suelo necesario para satisfacer la alimentación, productos forestales, para el gasto energético y ocupación directa de la superficie. La superficie se expresará en ha/cap/año, por habitante o por el conjunto de la comunidad. (Martínez, 2007), sin embargo, el cálculo de la huella ecológica tiene en cuenta el consumo y espacio público, en el caso del consumo sería: Consumo $(C)=$ Producción (P) + Importación (I) - Exportación (E). (Tobasura, 2008)

Para Guerrero y Guiñirgo (2008) la huella ecológica se mide en términos espaciales -hectáreas- y los consumos de alimentos, combustibles, productos forestales y suelo para la ocupación directa, además se requiere de espacios para disposición de residuos y el calor disipado, o sea, se determina por el consumo sobre la productividad del ítem, en lo cual es importante tener en cuenta la superficie necesaria para producir. (Guerrero \& Guiñirgo, 2008)

En síntesis, la huella ecológica sería igual a la matriz: energía, vivienda y servicios más el consumo proteico: carnes, huevos, aceites y grasas más el consumo de lácteos, cereales y hortalizas, entre otros.

De igual manera existen otros indicadores como la Biocapacidad, la cual corresponde a la capacidad de una zona para generar el abastecimiento de recursos renovables y absorber los desechos resultantes del consumo. (Rosso, 2010) También se habla del modelo DPSIR (Fuerza-Presión-Estado-Impacto-Respuesta) definido por Bowen como un indicador "diseñado para comunicar cómo diferentes actividades humanas interactúan con los sistemas naturales y para facilitar la discusión entre tomadores de decisión y grupos de interés" (Cárcamo et al, 2011).

Algunos autores hablan de modelos, como el de Galarraga "La Contabilidad de Flujos de Materiales, la cual "sirve para abordar la actividad económica desde una perspectiva biofísica en vez de monetaria. Desde esta óptica se explora la relación entre la economía y el ambiente, 
de tal forma que se identifica al sistema económico como un subsistema del ambiente, al que entran materia y energía y del que salen productos, residuos materiales y calor disipado" (Galarraga, 2006). Además, está el modelo DPSIR (Driving force, Pressure, State, Impact and Response) o, factor determinante, presión, estado, impacto y respuesta, es sencillo, de explicación de las relaciones entre el hombre y su entorno, basado en el modelo PER (Presión, Estado, Respuesta) propuesto por la OCDE. (Polanco, 2006).

Al igual que con la deuda ecológica, pensándose en fijar responsabilidades empresariales por el deterioro de la naturaleza ha articulado la expresión de pasivo ambiental, que a la luz de las concepciones tradicionales pareciera un sinónimo, sin embargo son expresiones utilizadas en connotaciones de responsabilidad diferente, una surge para establecer responsabilidades entre Estados y la otra para establecer responsabilidades en los actores sociales dentro del Estado, de ahí la importancia de referirla en este documento.

\section{A MODO DE CONCLUSIÓN}

Deuda ecológica, pasivo ambiental o eco-deuda: Para entender la diferencia de las expresiones, deuda ecológica y pasivo ambiental, es sustancial revisar la etimología de los términos que constituyen las expresiones y la apropiación que se ha hecho en su uso, con el propósito de orientar acciones en favor de la defensa del medio ambiente.

En el diccionario etimológico de Chile, la palabra Deuda viene del latín debita y esta del vocablo dehibere que significa "tener sin tener", lo cual define la obligación de pagar o devolver algo. Por otro lado, Ecología es la ciencia que estudia las relaciones de los seres vivos entre sí y con el medio y, es un neologismo acuñado por el alemán Ernest Haeckel (1834- 1919) usando las palabras griegas oikos y logos (oikos = casa y logos= estudio de) lo cual significa el estudio de la casa, naturaleza, interpretado hoy como el estudio de la naturaleza, es decir estudio de las relaciones de los seres vivos y su contexto físico en consecuencia ecológica es relativo a la ecología. Al unir los dos conceptos, se obtendría que "deuda ecológica" se define como "la obligación de pagar lo relativo al estudio de las relaciones de los seres vivos", sin embargo, ecológica se ha popularizado como "que protege el ambiente" lo que permite deducir que Deuda Ecológica es la obligación de pagar por la protección del ambiente. Aunque se ha popularizado como la deuda entre Estados por el deterioro de la naturaleza o el ambiente, especifica de países industrializados con países del tercer mundo.

En el caso de Pasivo según el glosario de términos de la IASCF, "es una obligación presente de la entidad, surgida a raíz de sucesos pasados, al vencimiento de la cual, espera desprenderse de recursos que incorporan beneficios económicos" $\mathrm{y}$, ambiental viene del latín ambientalis que significa "relativo a lo que abarca el entorno", por tanto, pasivo ambiental es la obligación de pagar por lo que abarca el entorno. Sin embargo, se ha popularizado como pasivo por el daño ambiental que realiza la empresa.

Ahora bien, aunque se toman la deuda ecológica y el pasivo ambiental, como dos acepciones diferentes, al revisar las definiciones de pasivo y deuda, son coincidentes (Sinónimos), que implican la existencia de un compromiso a pagar de un deudor a un acreedor, que se declara existente cuando se identifica un valor y el compromiso. 
En este sentido, la deuda ecológica que surge por la afectación ambiental, local y planetario, así como el expolio de la naturaleza en relaciones internacionales, al igual que los pasivos ambientales, pero en relaciones internas de cada país, aun significando lo mismo, de ahí que sea acertado el establecimiento de expresiones que revelen la realidad en la de las actividades humanas con la naturaleza y la condición de pasivo o deuda se reconoce con el compromiso y responsabilidad asumida por un deudor y la identidad de un acreedor que siempre será el Estado, de manera integral o en segmentos.

En particular serian una alternativa a revisar la expresión "Eco-deuda" la cual etimológicamente significa "La deuda con la casa o naturaleza"; que al momento de establecer responsables se convertiría en Pasivos por eco-deuda en el cual el acreedor es la autoridad ambiental que lo exige (Estado) para el caso de afectación de actores sociales internos y, Deuda externa por eco-deuda en el caso entre naciones.

Para terminar, independiente de la definición que se asuma, implica reconocer un deudor y un acreedor, pero ¿de qué valor?, y ¿quién le debe a quién, si todas las actividades humanas contaminan?, como se asigna la responsabilidad sobre el valor atribuido como deuda. Para dar respuesta a estos interrogantes, se debe avanzar en la adopción de un sistema de información contable ambiental, soportado en la valoración aproximada de las condiciones y cambios en la relación naturaleza, hombre economía, que sea georreferenciado.

\section{REFERENCIAS BIBLIOGRÁFICAS}

Aguilera, J. R. (2006). Sembrando Desiertos. La deuda social y ecológica generada por el endeudamiento externo en el Proyecto de Propósito Múltiple. Acción Ecológica, 19.

Aguillon, R., Bassey, N., Bravo, E., Donoso, A., Iyaye, F., Martínez, E., ... Russi, D. (2004). ¡No más saqueo y destrucción!:nosotros, los pueblos del Sur somos acreedores de la deuda ecológica. Alianza de los pueblos del Sur acreedores de la deuda ecológica, 251.

Albert, L. (2004). Contaminación ambiental. Origen, clases, fuentes y efectos. Revista de la facultad de salud pública y nutrición, 228-231.

Alonso, J. A. (2013). El Planeta Tierra en peligro: Calentamiento Global, Cambio Climático, Soluciones. Editorial Club Universitario.

Azam, G. (2010). Le temps du monde fini: [vers l'après-capitalisme]. Les liens qui libèrent.

Azamar Alonso, A., \& Carrillo González, G. (2017). Extractivismo Y Deuda Ecológica En América Latina. Luna Azul núm. 45, 400-418.

Azamar Alonso, A., \& Ponce Sánchez, J. (2014). El neo extractivismo como modelo de crecimiento en America Latina. Economía y desarrollo.

Balanyá, B., \& Ortega, M. (2005). La deuda ecológica española, Impactos ecológicos y sociales de la economía española en el extranjero. Sevilla: Muñoz Moya Editores Extremeños.

Barcena, I., Lago, R., \& Villalba, U. (2009). Energía y deuda ecológica, Transnacionales, cambio climático y alternativas. Barcelona: Icaria. 
Brito, R. S. (2015). La Relación Entre la Ética Ambiental y la Carta Encíclica Laudato Sí. Terra Mundus, 2(2).

Bullard, N. (2010). La deuda climática como una estrategia política subversiva. América Latina en Movimiento, 454, 17-19.

Cabrera, J. A., \& Zuaznábar, R. (2010). Impacto sobre el ambiente del monocultivo de la caña de azúcar con el uso de la quema para la cosecha y la fertilización nitrogenada. I. Balance del Carbono. Cultivos Tropicales, 31(1), 00-00.

Cárcamo, P., Cortés, M., ORTEGA, L., SQUEO, F. A., \& Gaymer, C. F. (2011). Crónica de un conflicto anunciado: Tres centrales termoeléctricas a carbón en un hotspot de biodiversidad de importancia mundial. Revista chilena de historia natural, 84(2), 171-180

Claros Henríquez, R. A., Huezo Santos, D., \& Otero Flores, A. M. (2009). Impuestos ecológicos como mecanismos de protección del medio ambiente (Doctoral disertación, Universidad de El Salvador).

Diccionario etimológico de Chile. Recuperado de http/etimologias.dechile.net/

Dillon, John. (2000). Deuda ecológica. El sur dice al norte: ¡Es hora de pagar! Ecología Política, España, 21. P131-152

Donoso, A. (2000). Deuda externa, mecanismo de dominación y saqueo. Ecuador: Acción Ecológica. Disponible en: http://www.accionecologica.org/deuda-ecologica/alertas/442-106-deudaexterna -mecanismo-de-dominacion-y-saqueo

Figueroa, J. R. (2012). El ser humano: sujeto moral de la ética ecológica. Revista Interciencia, vol. 37, núm. 1, enero, 2012, pp. 75-80. Caracas.

Galárraga, M. C. V. (2006). Estructura biofísica de la economía ecuatoriana: un estudio de los flujos directos de materiales. Revibec: revista iberoamericana de economía ecológica, 4, 55-72.

Global Footprint Network (2001). Estudio revela que la tierra entra en "Deuda Ecológica", al consumir su presupuesto de recursos. IEP, Instituto de Ecología Política. España. Disponible en: http://www. iepe.org/2011/09/la-tierra-entra-en-deuda-ecologica-al-consumir-su-presupuesto-de -recursos/

Gonzalez de Molina, N. (2000). La crisis de la modernidad historiográfica y el surgimiento de la Historia Ecológica. História e Meio-ambiente. O impacto da expansao europeia, 17-52.

Gracia, Carmen (2012). Gaia, El Jardín de Edén, y los fundamentos míticos y culturales del Paraíso, Revista ARS Longa, $\mathrm{N}^{\circ}$ 21, 253 - 267

Guerrero, E., \& Guiñirgo, F. (2008). Indicador espacial del metabolismo urbano. Huella ecológica de la ciudad de Tandil Argentina. Revista iberoamericana de economía ecológica, 31-44.

Guimaraes, R. (1992). El discreto encanto de la cumbre de la tierra. Evaluación impresionista de Río.

Hinojal, I. B., \& Aurrecoechea, R. L. (2008). Deuda ecológica vs Responsabilidad social corporativa: las empresas transnacionales ante la crisis socio-ecológica. Lan harremanak: Revista de relaciones laborales, (19), 141-168.

Kapp, K. (1970). Environmental disruption and social costs: a challenge to economics. Kyklos.

Lanuza, M., Moreno, R., \& Larin, Z. (2007). Una aproximación a la deuda ecológica de la Unión Europea con Centroamérica. Unidad ecológica salvadoreña, 46. 
Le Quang, M. (2015). El sentido político de la Iniciativa Yasuní-ITT: disputa entre capitalismo verde y ecosocialismo. Theomai, (32).

Leopold, A. (1970). A Sand County Almanac. Nueva York: Ballantine.

Lerussi, Natalia Andrea. (2015), Hacia una revisión del antropocentrismo kantiano Argumentos para una consideración ética de la naturaleza (orgánica), según la "Crítica de la facultad de juzgar teleológica", ideas y valores · vol. lxiv · №158. 123-141

Mantilla Pinilla, E. (2006). La contabilidad ambiental en el desarrollo sostenible. Revista Legis de Contabilidad y Auditoría, 25, 133-160.

Mantilla Pinilla, E., Verjel Portillo, C. y López García, J. V., (2005) "Medición de la sostenibilidad ambiental" Educc, Bogotá

Martínez Alier, J. (2005). El ecologismo de los pobres: Conflictos ambientales y lenguajes de valoración. Barcelona: Icaria: Icaria editorial.

Martínez Alier, J., \& Oliveres, A. (2003). ¿Quién debe a quién? Deuda ecológica y deuda externa. Icaria, 21.

Martínez Castillo, R. (2007). Algunos aspectos de la huella ecológica. Intersedes: Revista de las sedes regionales Vol VIII, 11-25.

Martínez Rodríguez, M. C., Valdez, R., Izchel, M., \& Morel Franco, N. (2015). Analisis de la nueva propuesta del PNUD y la encíclica verde, contextos ambientales internacionales.

Martínez, Alier, J. (1998). Deuda ecológica vs. deuda externa: Una perspectiva latinoamericana. Universidad Politécnica de Catalunya, 20.

Martínez, E., Acción Ecológica. (2003). ¿Cuánto cuesta la vida? El Oriente es un mito, 130.

Marx, K. (1973). El capital. México: Fondo de cultura económica.

Paredis E. et al. (2004) Elaboration of the concept of ecological debt. VLIR-BVO project. Final Report. Centre for Sustainable Development. Ghent University. VODO.

Pirela, B. S. (2009). Desafíos del quehacer ecológico-filosófico latinoamericano. Omnia, 15(1).

Polanco, C. (2006). Indicadores ambientales y modelos internacionales para toma de decisiones. Gestion y ambiente, 9(2).

Pérez, C.I.; Umaña Quesada, A. Centro Latinoamericano de Competitividad y Desarrollo Sostenible, Alajuela (Costa Rica). Alajuela (Costa Rica). 1996. 205 p. Universidad Nacional Agraria, CENIDA, Managua, Nicaragua.

Rodríguez Morales, V., Bustamante Alfonso, L. M., \& Mirabal Jean-Claude, M. (2011). La protección del medio ambiente y la salud, un desafío social y ético actual. Revista Cubana de salud pública, 37, 510-518.

Rosso, A. (2010). ¿Cuán grandes son nuestros pies? Programa Huella Ecológica y Biocapacidad Argentina. INTI, Obtenido el, 15 párrafo 2.

Rubio M, O., Ojeda J, J., \& Montes, E. (2003). deuda externa, inversión y crecimiento en Colombia 1970-2002. Bogotá: Banco de la república. 
Russi, D., Ventosa, I., Ramos, M. J., Ortega Cerda, M., \& Ungar, P. (2003). Deuda ecológica: ¿Quién debe a quién? Barcelona: Icaria editorial SA.

Shiva, V. (2001). Biopiratería: el saqueo de la naturaleza y del conocimiento (Vol. 170). Icaria Editorial.

Sunkel, O., \& Paz, P. (1999). El subdesarrollo latinoamericano y la teoría del desarrollo. Siglo xxi.

Tibán Guala, L. (2004). Género y sustentabilidad: Nuevos conceptos para el movimiento indígena. Polis, Revista de la Universidad Bolivariana, 3(9).

Tobasura, A. I. (2008). Huella ecológica y biocapacidad: Indicadores biofísicos para la gestión ambiental. Revista Luna Azul, 119-136.

Wackernagel, M., \& Rees, W. (2008). Our ecological footprint: Reducing human impact on the earth. Gabriola island BC and Philadelphia, Revista Luna Azul No 26, 134.

Zacher, M. (1992). The decaying pillars of the Westphalian temple: Implications for international order and governance. Cambridge: James N. Rosenau and Ernst-Otto Czempiel, Governance without government: order and change in world plitics. Cambridge Studies in International Relations 20.

\section{Para citaciones:}

Mantilla, E., Carbal, A., Gutiérrez, B. y Mejía, L. (2018). Sintagma gnoseológico de la deuda ecológica. Panorama Económico, 26(4), 459-480.

\section{AUTORES}

Eduardo Mantilla-Pinilla

\section{Adolfo Enrique Carbal-Herrera}

